\title{
Red cell distribution width as a prognostic marker in diabetes; a pilot cross-sectional study
}

\author{
Saeed Shirali ${ }^{\circledR}$, Sara Bahadoram ${ }^{2}$, Seyed Mohamad Kazem Nourbakhsh ${ }^{3}$, Mohammad Bahadoram ${ }^{4^{*}}$, \\ Ali Asghar Valipour ${ }^{5}$, Fatemeh Javanmardi ${ }^{6}$ \\ ${ }^{1}$ Hyperlipidemia Research Center, Department of Laboratory Sciences School of Paramedical Sciences, Ahvaz Jundishapur University of \\ Medical Sciences, Ahvaz, Iran \\ ${ }^{2}$ Department of Pediatrics, Imam Khomeini Hospital Complex, Tehran University of Medical Sciences, Tehran, Iran \\ ${ }^{3}$ Department of Pediatric Hematology and Oncology, School of Medicine, Tehran University of Medical Sciences, Tehran, Iran \\ ${ }^{4}$ Medical Student Research Committee, Faculty of Medicine, Ahvaz Jundishapur University of Medical Sciences, Ahvaz, Iran \\ ${ }^{5}$ School of Public Health, Abadan School of Medical Sciences, Abadan, Iran \\ ${ }^{6}$ Division of Epidemiology and Biostatistics of Department of Ahvaz Jundishapur University of Medical Sciences, Ahvaz, Iran
}

\section{A R T I C L E I N F O}

\section{Article Type:}

Original

\section{Article History:}

Received: 20 August 2018

Accepted: 3 November 2018

ePublished: 18 November 2018

\section{Keywords:}

Red cell distribution width

Type 2 diabetes

Hyperglycemia

\begin{abstract}
A B S T RA C T
Introduction: Red cell distribution width (RDW) is one of the important factors in anisocytosis which is related to impairment of erythropoiesis and degradation of erythrocytes.

Objectives: The aim of this study was to evaluate the use of RDW as a prognostic marker in diabetic patients.

Patients and Methods: This cross-sectional study was conducted on 144 individuals who referred to laboratories in Khuzestan. Of all, 69 persons were diabetic patients and 75 were non-diabetic.

Results: The mean fasting blood sugar (FBS) and RDW coefficient of variation (RDW-CV), were $85.20 \pm 9.12 \mathrm{mg} / \mathrm{dL}$ and $13.26 \pm 0.69 \%$ respectively, in the non-diabetic group, and 238.65 $\pm 70.54 \mathrm{mg} / \mathrm{dL}$ and $13.50 \pm 0.74 \%$ respectively, in the diabetic group. In this study, a significant difference of mean FBS $(P<0.001)$ and mean RDW $(P=0.04)$ between groups were detected. Conclusion: In our study, a significant relationship between changes in RDW and changes in blood sugar in diabetic patients was detected. Studying RDW in diabetes delineated higher RDW values than in healthy population. Therefore, it can be recommended to apply serum RDW as a prognostic marker for diabetes. However additional studies on this subject are necessary.
\end{abstract}

Implication for health policy/practice/research/medical education:

Red cell distribution width (RDW) is a predict incident in diabetics patients. Additionally patients with diabetes have higher RDW than patients without diabetes.

Please cite this paper as: Shirali S, Bahadoram S, Nourbakhsh MK, Bahadoram M, Valipour AA, Javanmardi F. Red cell distribution width as a prognostic marker in diabetes; a pilot cross-sectional study. J Nephropharmacol. 2019;8(1):e03. DOI: 10.15171/npj.2019.03

\section{Introduction}

Red cell distribution width (RDW) is typically measured by automated laboratory tools. It represents the variation in the size of red blood cells (RBCs) (anisocytosis) and the heterogeneity in the volume of RBCs. RDW is calculated as follows; standard deviation of RBC size/ mean corpuscular volume (1).

In other words, RDW represents a numerical measurement of the variation in RBC size. It is a strong prognostic factor in patients with heart failure and in patients with myocardial infarction, before the incidence of any symptom even after matching with hematocrit
(2). It is commonly used in the hematologic laboratory for the differential diagnosis of anemia. However, recent evidence suggests that anisocytosis is a common factor in human disorders such as cardiovascular diseases (CVDs), venous thromboembolism, cancer, diabetes, pneumonia, chronic obstructive pulmonary disease, liver and kidney failure, and also in other acute or chronic conditions (3). The normal RDW coefficient of variation (RDW-CV), is between $11.5 \%$ to $14.5 \%$. Its elevated level indicates an increase in the variations in cell size (4).

Diabetes mellitus (DM) is a chronic metabolic disorder characterized by hyperglycemia that is caused by a defect 
in the secretion or action of insulin, or both. Chronic hyperglycemia, which occurs in DM, is associated with dysfunction and disability of organs, especially eyes, kidneys, nerves, heart, and blood vessels. Hyperglycemia has several effects on RBCs, including cell swelling and reduced cell half-life (5). There are two types of DM; 1) type I diabetes that is commonly observed in children and adults and is related to insulin defects, and 2) type II diabetes that occurs in adults and accounts for more than $90 \%$ of all cases of diabetes in the world. The risk factors for type 3 diabetes include low activity, obesity, and aging (6). Nowadays, type 2 diabetes is one of the most common and complicated problems of the community. The disease has affected hundreds of millions of people all over the world and has created serious socioeconomic problems. The pathogenesis of type 2 diabetes is associated with the progression of insulin resistance in peripheral tissues and liver, decrease in $\beta$ cell mass, and deficiency in insulin secretion. Type 2 diabetes is markedly associated with reduction in insulin, which is not only due to the poor performance of pancreatic cells, but also due to the decrease in cell volume. Hyperglycemia has several effects on RBCs, besides formation of glycated hemoglobin, it leads to reduced deformability, changes in mechanical properties of RBCs, increased adhesion, and increased osmotic fragility, leading to changes in erythrocyte structure and hemodynamic characteristics $(7,8)$. Longterm (chronic) increase in glucose in diabetes is the main cause of angiopathic and neuropathic disorders, retinopathy, weak antioxidant defense system, metabolic disorders, and changes in lipid profiles. DM can be diagnosed by measuring fasting blood sugar (FBS) (>126 $\mathrm{mg} / \mathrm{dL}$ ). Among the symptoms of hyperglycemia, we may note over-drinking, over-urinating, over-eating, and weight loss (9). Diabetes is associated with increased risk of microvascular and macrovascular complications (10, 11). CVD is the leading cause of death among patients with diabetes accounting for $30 \%-40 \%$ of deaths $(12,13)$. RDW higher than $15 \%$ was associated with approximately 10 -fold increase in mortality, thus serving as a powerful tool for risk stratification in this high-risk group. The change in RDW could potentially serve as a surrogate marker for all-cause and cardiovascular mortality that could be used in pilot studies of primary and secondary prevention of CVD in diabetes (14).

\section{Objectives}

The aim of this study was to evaluate the efficacy of RDW as a prognostic marker in diabetic patients.

\section{Patients and Methods \\ Patients}

This cross-sectional study was conducted on the results of FBS and CBC tests which were conducted on 144 individuals who referred to laboratories in Khuzestan (from 2013 to 2014). In this study, blood was taken to conduct $\mathrm{CBC}$ test and to measure blood glucose. After performing the $\mathrm{CBC}$ test, the data on a variety of parameters such as such as hemoglobin, hematocrit, mean corpuscular volume (MCV), RDW, mean corpuscular hemoglobin $(\mathrm{MCH})$, and platelets were obtained by a simplex apparatus model KX21. The measurement of serum glucose level was conducted by an auto-analyzer apparatus via enzymatic colorimetric methods (Pars Azmon kit).

\section{Ethical issues}

Study-related data was delivered to subjects and informed consent was provided before the study. The research followed the Tenets of the Declaration of Helsinki. The Ethics Committee of Ahvaz Jundishapur University of Medical Sciences approved this study.

\section{Statistical analysis}

Statistical analyses were performed using SPSS18 software (SPSS Inc., Chicago, IL, USA). Quantitative continuous variables were indicated by mean \pm SD. Independent sample $t$ test was used to compare the significant difference between study groups. Additionally, $P$ values less than 0.05 were considered as the level of significance.

\section{Results}

Of 144 individuals who referred to the laboratory, 69 persons were diabetic patients and 75 were non-diabetic. The mean FBS and RDW-CV were $85.20 \pm 9.12(\mathrm{mg} / \mathrm{dL})$ and $13.26 \pm 0.69(\%)$ respectively, in non-diabetic group. In addition, the mean hemoglobin and hematocrit, MCV and RBCs, and platelets were $13.44 \pm 1.65 \mathrm{~g} / \mathrm{dL}, 40.42$ $\pm 4.36 \%, 85.49 \pm 6.12 \mathrm{fl}, 4.68 \pm 0.59\left(\times^{106 \mathrm{ml}}\right)$, and 232.91 $\pm 59.47\left(\times^{106 \mu l}\right)$, respectively in the non-diabetic group (Table 1).

In diabetic group, the mean FBS and RDW were 238.65 $\pm 70.54 \mathrm{mg} / \mathrm{dL}$ and $13.50 \pm 0.74 \%$, respectively. In addition, the mean hemoglobin, hematocrit, MCV, RBC, and platelet were $13.36 \pm 1.44 \mathrm{~g} / \mathrm{dl}, 39.96 \pm 3.90 \%, 86.63$ $\pm 4.45 \mathrm{fl}, 4.57 \pm 0.48\left(\times^{106 \mathrm{ml}}\right)$, and $240.44 \pm 67.94\left(\times^{106 \mu l}\right)$ respectively (Table 1 ).

In this study, a significant difference of mean FBS ( $\mathrm{p}$ $<0.001)$ and mean RDW $(\mathrm{P}=0.04)$ between groups was detected.

\section{Discussion}

DM and hyperglycemia have different effects on RBC and HbA1c formation (15). DM is associated with osmotic adhesion (16). DM also causes oxidative stress, which causes red cell deformation, resulting in increased RDW levels (17).

In contrast to our results, in the study by Engström et al, the reduction in RDW was associated with an increase in the prevalence of diabetes. The reduction in RDW can be used as an alternative marker for the decrease in RBC survival (18). In a study by Dada et al in Nigeria, a 
Table 1. Results of analysis of various parameters in diabetic and nondiabetic groups

\begin{tabular}{|c|c|c|c|}
\hline \multirow{2}{*}{ Variable } & \multicolumn{2}{|c|}{ Groups (mean \pm SD) } & \multirow{2}{*}{$P$ value } \\
\hline & Diabetics $(n=69)$ & Non-diabetics $(n=75)$ & \\
\hline $\mathrm{FBS}(\mathrm{mg} / \mathrm{dL})$ & $238.65 \pm 70.54$ & $85.20 \pm 9.12$ & $<0.001$ \\
\hline RDW (\%) & $13.50 \pm 0.74$ & $13.26 \pm 0.69$ & $0.04 *$ \\
\hline $\mathrm{Hb}(\mathrm{g} / \mathrm{dL})$ & $13.36 \pm 1.44$ & $13.44 \pm 1.65$ & 0.77 \\
\hline Hct (\%) & $39.96 \pm 3.90$ & $40.42 \pm 4.36$ & 0.51 \\
\hline $\operatorname{MCV}(\mathrm{fl})$ & $86.63 \pm 4.45$ & $85.49 \pm 6.12$ & 0.20 \\
\hline $\operatorname{RBC}\left(x^{106 \mathrm{ml}}\right)$ & $4.57 \pm 0.48$ & $4.68 \pm 0.59$ & 0.22 \\
\hline Plt $\left(x^{106 \mu l}\right)$ & $240.44 \pm 67.94$ & $232.91 \pm 59.47$ & 0.54 \\
\hline
\end{tabular}

significant relationship between RDW and blood pressure was seen. However, contrary to our finding, no significant relationship between RDW and FBS was detected (6). Moreover, our findings in this study are inconsistent with the findings of other studies, such as the studies by Lee et al (19). In another study, the researchers evaluated RDW and serum BNP (B type natriuretic peptide) levels in diabetic patients with cardiac failure and compared them with healthy subjects. It was found that RDW levels in diabetic patients with cardiac failure were significantly higher than of healthy subjects (4). Finally, in a review study, Shirali et al detected the efficacy of RDW as a prognostic marker for diabetes (20). Similar results were found in Nada study, which RDW was considered as an inflammatory marker with a significant predictive value and is significantly higher in diabetic patients than healthy subjects (21).

\section{Conclusion}

In our, a significant relationship between changes in RDW and changes in blood sugar in diabetic patients was detected. Therefore, it can be suggested to apply serum RDW as a prognostic marker for diabetes. However additional studies on this subject are necessary

Limitations of study

This is a pilot study, which requires more investigations by larger studies.

\section{Acknowledgments}

This work is dedicated to the memory of Dr. Saeed Shirali, Head of the Student Research Committee of Ahvaz Jundishapur University of Medical Sciences.

\section{Authors' contribution}

$\mathrm{SS}, \mathrm{MB}$ and $\mathrm{SB}$; idea and writing the manuscript. AAV and MB; Literature Review. SMK; critique and thought. FJ; statistical analysis. All authors read and approved the final manuscript.

\section{Conflicts of interest}

The authors declare no conflict of interest.
Ethical considerations

Ethical issues (including plagiarism, misconduct, data fabrication, falsification, double publication or submission, redundancy) have been completely observed by the authors.

\section{Funding/Support}

This study was funded by Vice Chancellor of Research Affairs of Ahvaz Jundishapur University of Medical Sciences.

\section{References}

1. Li N, Zhou H, Tang Q. Red blood cell distribution width: a novel predictive indicator for cardiovascular and cerebrovascular diseases. Dis Markers. 2017;2017:7089493. doi: 10.1155/2017/7089493.

2. Qiu L, Chen C, Li SJ, Wang C, Guo F, Peszel A, et al. Prognostic values of red blood cell distribution width, platelet count, and red cell distribution width-to-platelet ratio for severe burn injury. Sci Rep. 2017;7:13720. doi: 10.1038/s41598-017-13151-3.

3. Yin $\mathrm{Y}$, Ye S, Wang H, Li B, Wang A, Yan W, et al. Red blood cell distribution width and the risk of being in poor glycemic control among patients with established type 2 diabetes. Ther Clin Risk Manag. 2018;14:265-273. doi: 10.2147/TCRM.S155753.

4. Sičaja M, Pehar M, Đerek L, Starčević B, Vuletić V, Romić $\check{Z}$, et al. Red blood cell distribution width as a prognostic marker of mortality in patients on chronic dialysis: a single center, prospective longitudinal study. Croat Med J. 2013;54:25-32.

5. American Diabetes Association. Diagnosis and classification of diabetes mellitus. Diabetes Care. 2013;36:S67-74. doi: 10.2337/dc13-S067.

6. Dada OA, Uche E, Akinbami A, Odesanya M, JohnOlabode S, Adediran A, et al. The relationship between red blood cell distribution width and blood pressure in patients with type 2 diabetes mellitus in Lagos, Nigeria. J Blood Med. 2014;5:185-9. doi: 10.2147/JBM.S67989.

7. Symeonidis A, Athanassiou G, Psiroyannis A, Kyriazopoulou V, Kapatais-Zoumbos K, Missirlis Y, et al. Impairment of erythrocyte viscoelasticity is correlated with levels of glycosylated haemoglobin in diabetic patients. Clin Lab Haematol. 2001;23:103-9.

8. Livshits L, Srulevich A, Raz I, Cahn A, Barshtein G, Yedgar $S$, et al. Effect of short-term hyperglycemia on protein kinase C alpha activation in human erythrocytes. Rev Diabet Stud. 2012;9:94-103. doi: 10.1900/RDS.2012.9.94.

9. Gavin III JR, Alberti K, Davidson MB, DeFronzo RA. Report of the expert committee on the diagnosis and classification of diabetes mellitus. Diabetes care. 1997;20:1183.

10. Selvin E, Marinopoulos S, Berkenblit G, Rami T, Brancati FL, Powe NR, et al. Meta-analysis: glycosylated hemoglobin and cardiovascular disease in diabetes mellitus. Ann Intern Med. 2004;141:421-31.

11. Kannel WB, Feinleib M, McNamara PM, Garrison RJ, Castelli WP. An investigation of coronary heart disease in families: the Framingham Offspring Study. Am J Epidemiol. 1979;110:281-90. 
12. Rao Kondapally Seshasai S, Kaptoge S, Thompson A, Di Angelantonio E, Gao P, Sarwar N, et al. Diabetes mellitus, fasting glucose, and risk of cause-specific death. N Engl J Med. 2011;364:829-841. doi: 10.1056/NEJMoa1008862.

13. Morrish NJ, Wang SL, Stevens LK, Fuller JH, Keen H. Mortality and causes of death in the WHO Multinational Study of Vascular Disease in Diabetes. Diabetologia. 2001;44:S14-21.

14. Al-Kindi SG, Refaat M, Jayyousi A, Asaad N, Al Suwaidi J, Abi Khalil C. Red cell distribution width is associated with all-cause and cardiovascular mortality in patients with diabetes. Biomed Res Int. 2017;2017:5843702. doi: $10.1155 / 2017 / 5843702$.

15. Barbieri J, Fontela PC, Winkelmann ER, Zimmermann CE, Sandri YP, Mallet EK, et al. Anemia in patients with type 2 diabetes mellitus. Anemia. 2015;2015:354737. doi: $10.1155 / 2015 / 354737$.

16. Chang HY, Li X, Karniadakis GE. Modeling of Biomechanics and Biorheology of Red Blood Cells in Type 2 Diabetes
Mellitus. Biophys J. 2017;113:481-490. doi: 10.1016/j. bpj.2017.06.015.

17. Lu YA, Fan PC, Lee CC, Wu VC, Tian YC, Yang CW, et al. Red cell distribution width associated with adverse cardiovascular outcomes in patients with chronic kidney disease. BMC Nephrol. 2017;18:361. doi: 10.1186/s12882017-0766-4.

18. Engström G, Smith JG, Persson M, Nilsson PM, Melander O, Hedblad B. Red cell distribution width, haemoglobin A $1 \mathrm{c}$ and incidence of diabetes mellitus. J Intern Med. 2014;276:174-83. doi: 10.1111/joim.12188.

19. Lee YH, Pratley RE. The evolving role of inflammation in obesity and the metabolic syndrome. Curr Diab Rep. 2005;5:70-5.

20. Abyaza S, Shirali S. RDW as a Novel prognostic Marker in Diabetic Patients. Persian J Med Sci. (PJMS). 2015;2:66-72.

21. Nada AM. Red cell distribution width in type 2 diabetic patients. Diabetes Metab Syndr Obes. 2015 30;8:525-33. doi: $10.2147 /$ DMSO.S85318.

Copyright $\odot 2019$ The Author(s); Published by Society of Diabetic Nephropathy Prevention. This is an open-access article distributed under the terms of the Creative Commons Attribution License (http://creativecommons.org/licenses/by/4.0), which permits unrestricted use, distribution, and reproduction in any medium, provided the original work is properly cited. 